\title{
Integrating Remote Sensing and GIS to Model Forest Fire Rik in Virunga Massif, Central - Eastern Africa
}

\author{
Kayijamahe, C. B. ${ }^{1}$, Rwanyiziri, G. ${ }^{2,3}$, Mugabowindek we, M. ${ }^{2}$, Tuyishimire, J. ${ }^{2}$ \\ ${ }^{1}$ International Gorilla Conservation Programme (IGCP), Gasabo District, P.O. Box: 931 Kigali, Rwanda \\ ${ }^{2}$ Centre for Geographic Information Systems and Remote Sensing (CGIS), College of Science and \\ Technology, University of Rwanda, Nyarugenge Campus. P.O: Box: 3900 Kigali, Rwanda \\ ${ }^{3}$ Department of Geography and Urban Planning, College of Science and Technology, University of \\ Rwanda, Nyarugenge Campus. P.O: Box: 3900 Kigali, Rwanda
}

* Correspondance: Kayijamahe Charles Birasa, Email: charlix07@ gmail.com

\begin{abstract}
This study aimed at developing a forest fire risk model using a combination of GIS and Remote sensing techniques, which helped to identify the level of forest fire vulnerability in Virunga Massif, located at the edge of central and eastern Africa. The Analytic Hierarchical Process (AHP) approach was employed to rank and weigh the key variables and combine them into different fire risk input factors which were later integrated into the main forest fire risk model. The main input datasets, which were linked with a potential source of a forest fire, include the land cover (specifically vegetation type data generated through the Landsat 8 image classification); topographic variables such as slope, elevation and aspect retrieved from the existing Digital Elevation Model (DEM) of Rwanda; the concentration of illegal activities and proximity to beehives sites; as well as visibility from the road and human settlements. Input factor maps were generated, assigned weights and combined in a GIS environment to produce a Virunga massif fire risk model map, which was validated using the existing burnt areas map, and ground truth points recorded using GPS. The study found that the ignition factors are the most forest fire triggering factors in Virunga massif, followed by topographic factors which play a major role in the fire spreading across the ecosystem. The high forest fire risk areas were found in steep slope location around the peaks of the volcanoes, whereas areas with the lowest risk of forest fire were found inside the forest at gentle slopes. The model was validated at $75 \%$ accuracy using ground truth data. The study proposes measure to halt the ignition factors through prevention of illegal activities in the Virunga massif for the successful prevention of the forest fire risk in the ecosystem, with much effort invested during the dry season, along with the relocation of beehives to a farther distance from the ecosystem's edge.
\end{abstract}

Keywords: Forest Fire Risk Modelling, Biodiversity, Illegal Activities, Ignition Factors, Topographic Factors, Analytic Hierarchy Process 


\section{Introduction}

Frequent forest fire is among the major challenges to forest resources degradation across the globe (Dong et al., 2006). Forest biodiversity richness for both flora and fauna, forest's ecological region, composition and functioning of the forest ecosystem are all compromised upon the occurrence of the forest fire (Jhariya, 2013; Leblon et al., 2012). It has been estimated that at least about 75 million to 820 million hectares of land are burnt every year (Larsen, 2009). Although climate change and variability has been recently mentioned among the major causes of the wildfires (IPCC, 2015), they have been increasable occurring either due to natural factors or as human-induced phenomena (Goldammer \& Jenkins, 1990; Nepstad et al., 1999; IUCN/WWF, 2000). Impact of the forest fires has been strongly studied in South America and South-East Asia, with a record of about 4.7 million hectares of natural forest burnt in Indonesia, especially in Sumatra and Borneo; and about 1.5 million hectares of forest burnt in Northern Bolivia in 1997 and 1998; and about 1.5 million ha of forest damaged in 1998 and 1999 in Mexico, Venezuela, Bolivia, Suriname Paraguay, Guyana and Colombia (Nepstad et al., 1999; Uhl et al., 1998; Grégoire et al., 1998). However, forest fires were understudied in African tropical mountain forests despite their rich biodiversity and ecological functions (Juárez-Orozco et al., 2017).

Under normal conditions, wildfires are unusual in the tropical forests because of the moist microclimates, low wind, moist fuel and high rainfall (Goldammer \& Price, 1998). Nevertheless, fires have recently been a major threat to the tropical forests and their biodiversity due to the changes in the man-induced fires and increased frequency in the El Niño phenomenon. Specifically, African tropical forest is highly prone to lightning storm and a fire climate with both dry and wet periods, and the tropical savannah suffers a lot from the fire caused by lightning as a source of ignition (FAO, 2001). The most renowned areas with tropical forests in Africa to suffer from wildfires are located in Northern Angola, the Southern Democratic Republic of the Congo, Southern Sudan, and the Central African Republic (Larsen, 2009).

In Virunga Massif, a biodiversity-rich ecosystem shared by the Democratic Republic of Congo, Rwanda, and Uganda, forest fires were not previously considered as a serious threat until the 2009 wildfire event. Poachers and honey collectors were previously renowned to be the cause for previous small fires in the ecosystem, which could be extinguished without considerable damage. These add to other socio-economic related challenges faced by the protected areas in the region, for which history and socio-economy plays a big part (Sabuhoro et al., 2020). The major forest fire in the history of the Virunga Massif occurred in 2009 starting from eastern Volcanoes National Park (Rwanda), and spread towards the Mgahinga Gorilla National Park (Uganda). The fire destroyed about 300 ha of the natural forests and was followed by severe ecological impacts on the forest. The impacts included the habitat loss, shrinkage and/or fragmentation for several animal species in the forest especially to the endangered mountain Gorillas (Gorilla beringei beringei), which resulted in the species migration to environmental conditions unfavourable to their survival (Kayijamahe, 2009).

Although the 2009 forest fire event was devastating, there was no information tool which could indicate potential areas of the Virunga massif exposed to more fire hazards, to enhance the 
preparedness towards fighting potential forest fire hazards in the ecosystem. Based on the possibilities to map and monitor forest fire risk zones to minimise the frequency of fire and hence avert damage (Johnson \& Gutsell, 1994; Jaiswal et al., 2002), this study has constructed a spatial model (map) of forest fire risk zones in the Virunga massif, by integrating remote sensing and GIS techniques, which helped indicate the level of vulnerability to the hazard by different areas of the ecosystem. This supports the fact that the forest fire management can be effectively achieved through the successful anticipation of the occurrence of the fire triggering factors which help to understand the dynamic behaviour of the hazard (Chuvieco \& Salas, 1996). The factors considered to achieve the study's objective were retrieved from the literature in addition to the information from the conservation experts working for the protection and conservation of Virunga massif. Nevertheless, due to the lack of accurate local weather data, the data were not included in the modelling process.

\section{Materials and Methods}

\subsection{Study Area}

Virunga Volcanoes Range (VVR) also known as Virunga massif, extends from $1^{\circ}$ and $2^{\circ}$ of latitude South and $29^{\circ}$ and $30^{\circ}$ of longitude East at the border of Democratic Republic of Congo, Rwanda and Uganda. As illustrated by Figure 1, the ecosystem is composed of three adjacent national parks namely Mikeno Sector of Virunga National Park (DRC), Volcanoes National Park (Rwanda), and Mgahinga Gorilla National Park (Uganda). It covers about $450 \mathrm{~km}^{2}$ and lies on 6 extinct volcanoes including, from East to West, Muhabura, Gahinga, Sabyinyo, Bisoke, Karisimbi, and Mikeno, falling in the altitudinal range of $1800 \mathrm{~m}$ and $4507 \mathrm{~m}$ above mean sea level. Along an ascending altitudinal gradient, the vegetation varies from bamboo at the lowest altitude to Afro-montane vegetation at the highest altitude. The vegetation of the Volcanoes National Park is divided into 5 main zones having altitudinal succession (Kajonjori, 1993) with mixed Forest $(1600-2800 \mathrm{~m})$, bamboo $(2500$ - $2800 \mathrm{~m})$, hagenia hypericum zone (2800 $3200 \mathrm{~m})$, subalpine zone $(3200-3600 \mathrm{~m})$, and alpine zone (above $3600 \mathrm{~m}$ ). 


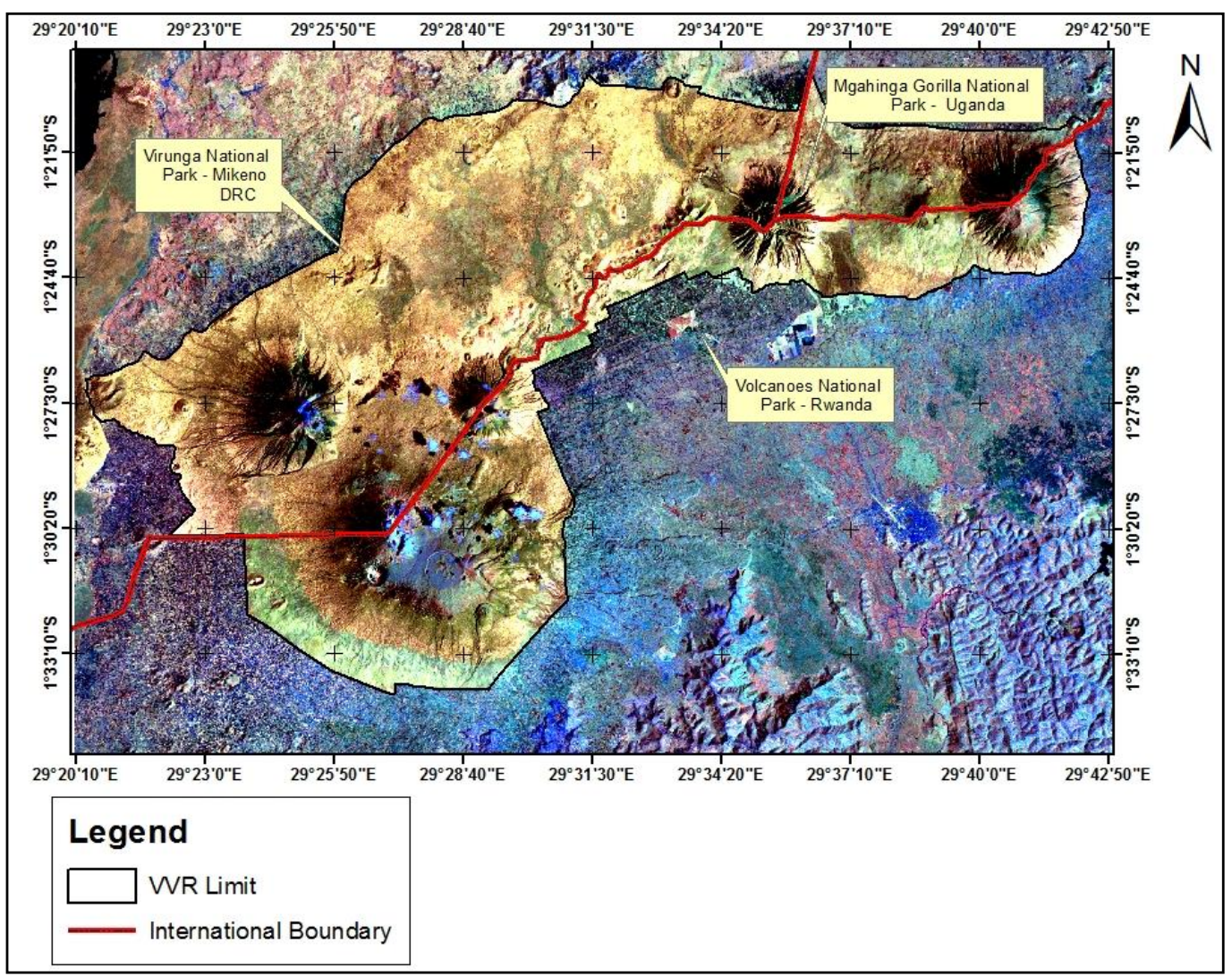

Figure 1: Map of the Study Area (Landsat ETM + Image)

\subsection{Data}

Landsat 8 images that were accessed from the USGS Earthexplorer database, were used to generate vegetation cover map. The existing $30 \mathrm{~m}$ resolution DEM was acquired from the Centre for GIS and Remote Sensing of the University of Rwanda (CGIS - UR), and it served the purpose of generating the relevant topographical factors including slope, aspect and elevation. Road network and human settlement in proximity to the Virunga massif were obtained from the National Institute of Statistics (NISR). Moreover, Ranger Based Monitoring (RBM) data which include the inventoried areas where forest fire have occurred in the past, have been provided by park management authorities from DRC (Institut Congolais pourla Conservation de la Nature ICCN for Parque National des Virunga - PNVi; Rwanda (Rwanda Development Board - RDB for Virunga National Park - VNP), and Uganda (Uganda Wildlife Authority - UWA for BwindiMgahinga Conservation Area - BMCA). Surveyed illegal activities and fire incidence point locations data were extracted from RBM, and they served as inputs into the spatial modelling validation processes.

Previously burnt areas were visited for field observations to assess the impacts and have the ground reality of the forest fire incidence occurrences, which also served the validation purpose. The beehives available in the forest were visited, since they are among the key ignition factor contributing to the forest fire incidence, especially during the honey harvesting process, and the fieldwork ended with 150 GPS locations recorded in the ecosystem. Finally, interviews were conducted with, first, people who were involved in the 2009 forest fire extinction process, and these included 12 staff from the three national parks (VNP, PNVi, and BMCA), 5 staff working 
for Conservation Non-Governmental Organizations (NGOs), and 5 members of local Community-Based Organizations (CBOs). The first interviews were conducted through face-toface discussion. The second interview was given to 10 conservation experts in the region but in a different setting, where they were given a list of potential factors contributing to the forest fire, and they were asked to rank them based on their relevance and level of impact to contribute to the occurrence or spread of the forest fire. The conservation experts included 5 staff from Volcanoes National Park (VNP), 2 staffs from International Gorilla Conservation Project (IGCP), 1 staff from Dian Fossey Gorilla Fund International-Karisoke Research Center (DFGFI-KRC), and 2 staffs from Mgahinga National Park (MGNP).

\subsection{Spatial Model Design}

Individual fire risk factors were identified and grouped into groups based on their similarities, as some previous studies have been successfully implemented with the same approach (Rathaur, 2006; Orozco et al., 2009; Burguess, 2011; Mohammed et al., 2009; Santiago and Kheladze, 2011; Mahdavi et al., 201 and Bharat, 2014). Each factor's relevance within the same group was assessed through the application of pairwise comparison based on the Analytic Hierarchy Process (AHP) approach (Saaty, 1980). This approach consists of comparing and ranking factors one against another in the same group of factors in $\mathbf{m} \mathbf{x} \mathbf{~ m}$ matrix, where $\mathrm{m}$ is the number of evaluation criteria considered. Each entry $\bar{a} \mathrm{jk}$ of matrix A represents the importance of the $\mathrm{j}^{\text {th }}$ criterion relative to the $\mathrm{k}^{\text {th }}$ criterion. The relative importance between the two criteria is measured according to a numerical scale from 1 to 9 (Table 1). Then, corresponding weights are generated based on each factor's relevance in the group following the following formula in equation (1) and equation (2):

$$
w_{j}=\frac{\sum_{l=1}^{m} \bar{a}_{j l}}{m} .
$$

Eq. 1

Finally, the final weight for each factor is built by averaging the entries on each row as follow:

$$
\bar{a}_{j k}=\frac{a_{j k}}{\sum_{l=1}^{m} a_{l k}} .
$$

Where $\overline{\mathrm{a}}_{j k}$ correspond to the weight of each entry in the matrix; $\mathrm{a}_{j k}$ corresponds to the rank generated by the pairwise comparison, $\mathrm{W}_{j}$ is the average weight of each factor; 1 is the sum of all weights in a column and is equal to 1 , and $\mathrm{m}$ is the number of factors considered.

Table 1: Relative Scores and Interpretation for the Model 


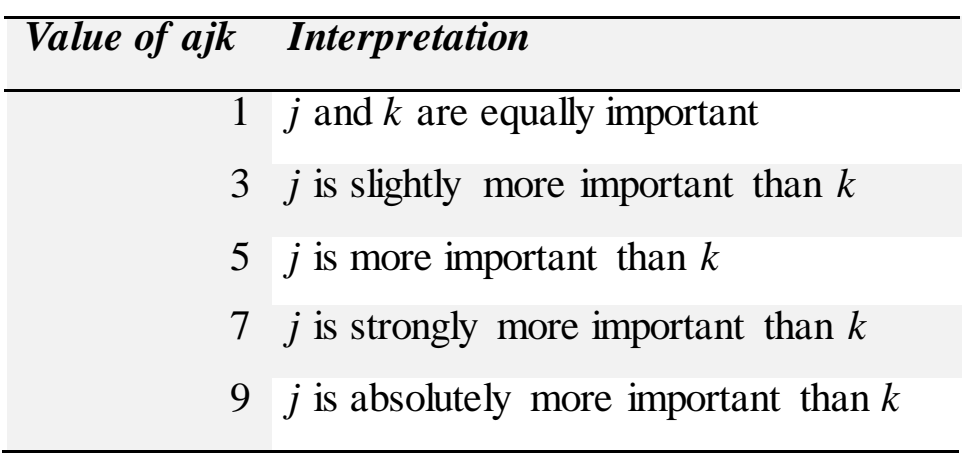

The ranks and weighs proposed by experts were validated using the consistency measures: Consistency Index and Consistency Ratio, which were both statistically significant at the $p=0.1$ ). Finally, the forest fire risk model was produced through the combination of all the groups of factors.

\subsection{Validation}

Two validation approaches were employed to assess the accuracy of the obtained forest fire risk model. First, field observations were used, where 150 GPS coordinates were collected from each of the fire risk zones, and where any fire event previously occurred. The field locations and the model points were used to generate the confusion matrix which was used to assess the accuracy of the model, as also applied in the previous study by Mohammed et al. (2009) and proved effective in forest fire risk model validation. Before the model validation, the input factor maps, especially the fuel input factor map which was composed of different vegetation classes, was validated using 130 GPS coordinates collected during the fieldwork. The vegetation classes were obtained using supervised classification on Landsat 8 image, and 12 classes were obtained: water, swamp grassland, ravines, alpine meadow, hagenia-hypericum forest, mixed forest, neobutonia forest, bamboo forest, brush ridge, herbaceous, mid-altitude grassland, and meadow savannah. The classification resulted in an overall accuracy of $75.38 \%$ with the Kappa statistic value of 0.71 , as elaborated by Table 2 . 
Table 2: Accuracy Assessment of the Vegetation Classification

\begin{tabular}{lllllll}
\hline Class & $\begin{array}{l}\text { Reference } \\
\text { Total }\end{array}$ & $\begin{array}{l}\text { Number } \\
\text { Correct }\end{array}$ & $\begin{array}{l}\text { Classified } \\
\text { Total }\end{array}$ & $\begin{array}{l}\text { Producers } \\
\text { Accuracy }\end{array}$ & $\begin{array}{l}\text { Users } \\
\text { Accuracy }\end{array}$ & Kappa Value \\
\hline Water & 2 & 2 & 2 & 100 & 100 & 1 \\
Swamp Grassland & 3 & 4 & 3 & 100 & 75 & 0.71 \\
Ravines & 3 & 3 & 2 & 66.67 & 66.67 & 0.58 \\
Alpine Meadow & 10 & 9 & 9 & 90 & 100 & 1 \\
Hagenia-Hypericum Forest & 26 & 30 & 21 & 80.77 & 70 & 0.66 \\
Mixed Forest & 18 & 14 & 10 & 55.56 & 71.43 & 0.7 \\
Neobutonia Forest & 6 & 5 & 5 & 83.33 & 100 & 1 \\
Bamboo Forest & 20 & 26 & 18 & 90 & 69.23 & 0.72 \\
Brush Ridge & 17 & 15 & 12 & 70.59 & 80 & 0.78 \\
Herbaceous & 14 & 13 & 9 & 64.29 & 69.23 & 0.67 \\
Mid-Altitude Grassland & 6 & 5 & 4 & 66.67 & 80 & 0.8 \\
Meadow Savannah & 5 & 4 & 3 & 60.00 & 75 & 0.72 \\
Total & $\mathbf{1 3 0}$ & $\mathbf{1 3 0}$ & $\mathbf{9 8}$ & & & \\
Overall Classification Accuracy & $\mathbf{7 5 . 3 8 \%}$ & & & & & \\
Overall Kappa statistics $=0.71$ & & & & & \\
\hline
\end{tabular}

Using the expert knowledge (from the survey results), fire risk index was attributed to each vegetation class-based to its flammability potential, and water was assigned 0 since it is not flammable, swamp grassland: 1, ravines: 2, Alpine meadow: 3, hagenia-hypericum forest: 4, mixed forest: 5, neobutonia forest: 6 , bamboo forest: 7 , brush ridge: 8 , herbaceous: 9, midaltitude grassland: 10, and meadow/savannah was given 11 since it is highly flammable. The second validation was constituted by overlaying the locations of the burnt areas with the produced forest fire risk model, and from here it was possible to assess the degree to which the spatial model (forest fire risk map) agrees with the burnt area map. This second validation approach showed that $18.75 \%$ of burnt locations were in the high-risk zone, $48.75 \%$ in Moderate risk zone while $32.5 \%$ were in the low-risk zone (table 3 ).

Table 3: Confusion Matrix Table

\begin{tabular}{|c|c|c|c|c|c|c|c|c|c|}
\hline & Model & $\begin{array}{l}\text { Very } \\
\text { Low }\end{array}$ & Low & Moderate & High & $\begin{array}{l}\text { Very } \\
\text { High }\end{array}$ & Total & $\begin{array}{l}\text { Error of } \\
\text { Omission }\end{array}$ & $\begin{array}{l}\text { Producer } \\
\text { Accuracy }\end{array}$ \\
\hline \multirow[t]{9}{*}{ Reference } & Very Low & 25 & 3 & 2 & 1 & 1 & 32 & 21.88 & 78.13 \\
\hline & Low & 2 & 22 & 2 & 3 & 2 & 31 & 29.03 & 70.97 \\
\hline & Moderate & 1 & 1 & 24 & 2 & 3 & 31 & 22.58 & 77.42 \\
\hline & High & 1 & 3 & 1 & 21 & 4 & 30 & 30 & 70 \\
\hline & Very High & 1 & 1 & 1 & 3 & 20 & 26 & 23.08 & 76.92 \\
\hline & Total & 30 & 30 & 30 & 30 & 30 & 150 & & \\
\hline & $\begin{array}{l}\text { Error of } \\
\text { Omission }\end{array}$ & 16.67 & 26.67 & 20 & 30 & 33.33 & & & \\
\hline & $\begin{array}{l}\text { Producer } \\
\text { Accuracy }\end{array}$ & 83.33 & 73.33 & 80 & 70 & 66.67 & & & \\
\hline & & & & \multicolumn{2}{|c|}{ Overall Accuracy = } & 0.75 & & & \\
\hline
\end{tabular}




\section{Results}

\subsection{Forest Fire Risk Model Input Factor Maps}

The final spatial modelling of forest fire risk in Virunga massif was constructed using 4 input factor maps namely: field risk factor, topographic risk factors (contributing especially to the fire spread), ignition risk factors, and detection risk factor maps, as elaborated in the following sections.

\section{a. Fuel Risk Factor}

The fuel risk factor map was composed of vegetation classes. These were obtained through the supervised classification of the Landsat 8 image, which resulted in 12 vegetation classes which include, bamboo forest, Hagenia-Hypericum forest, mixed forest, Neobutonia forest, herbaceous vegetation, brush ridge, Alpine meadow, ravines, meadow/Savannah, swamp grassland, midaltitude grassland, and waterbody. From Figure 7. a., it is clear that the highly and easily flammable vegetation types: brush ridge, herbaceous, mid-altitude grassland, and meadow/savannah are found across the ecosystem especially in the North and Southern parts. On Rwanda side, highly flammable vegetation (meadow savannah) is observed densely in the Southwest of Kalisimbi volcano. With 0 indicating the non-flammable cover and 11 indicating the highly and easily flammable cover, the following are the index values assigned to every land cover in the Virunga massif: water: 0, Swamp Grassland: 1, Ravines: 2, Alpine Meadow: 3, Hagenia-Hypericum forest: 4, Mixed forest: 5, Neobutonia Forest: 6, Bamboo forest: 7, Brush ridge: 8, Herbaceous: 9, Mid-altitude Grassland: 10, and Meadow/Savannah: 11.

\section{b. Topographic Risk Factors (Fire Spread)}

\section{Slope}

The slope variation of Virunga massif was extracted from existing $30 \mathrm{~m}$ resolution DEM of Rwanda and was reclassified into 9 classes (Figure 4. a.) based on Heikkilä, et al (2010) slope classification process, which suggests that the rate of spread doubles at $10^{\circ}$ increase of slope, and doubles again at $15^{\circ}$, and $30^{\circ}$, and for every 10 more degrees.

The obtained slope classes (Figure 4. a.) were attributed fire risk indexes where the areas with a slope ranging between 0 and 5\% were attributed 1 as fire risk index, meaning that the slope in these areas contributes very low to the spread of the fire. Then index for areas with $5.1-10 \%$ was $2,10.1-15 \%$ was given $3,15.1-20 \%$ was given $4,20.1-25 \%$ was assigned $5,25.1-30 \%$ was given 6, 30.1 - 35\% was assigned 7, areas with a slope ranging between 35.1 and $40 \%$ were assigned 8 , and the areas with a slope above $40 \%$ was assigned an index value of 9 , meaning that they contribute the highest to the spread of forest fire. 


\section{Elevation}

Elevation map was produced using the existing 30 resolution DEM of Rwanda, and it showed that areas around volcanoes cones are attributed with the highest elevations (Figure 4. b.), and thus contribute much to the spread of the fire. As the highest elevations are found around the volcanoes cones, these areas were also attributed with the highest index value, indicating their highest contribution to the spread of the forest fire. The elevation map indicated that about $44.4 \%$ of the Virunga massif areas are located in the elevation range between $1800 \mathrm{~m}$ and $2600 \mathrm{~m}$ above sea level, which is actually at low altitudes compared to the rest of the ecosystem. The attribution of forest fire risk index resulted in areas with altitudes above $3400 \mathrm{~m}$ being associated with 1 as forest fire risk index; 3001 - $3400 \mathrm{~m}$ was given 2; $2601-3000 \mathrm{~m}$ was associated with 3; 2201 $2600 \mathrm{~m}$ was attributed 4, and the lowest altitudes ranging between 1800 and $2200 \mathrm{~m}$ were associated with 5 indicating their potential to spread the forest fire

\section{Aspect}

Aspect has also been recognised as one of the topographic factors contributing to the spread of forest fire. The aspect map was produced using the $30 \mathrm{~m}$ resolution DEM and reclassified in 9 classes (Figure 4. c.) before proceeding with attribution of the corresponding forest fire risk index. About 38.2\% of the Virunga massif has areas with slopes facing West, South, South-East, and South-West which are associated with a high risk of the forest fire. Areas with slopes facing North $\left(0-22.5^{\circ}\right)$ were associated with forest fires risk index of 1 ; North-East $\left(22.5-67.5^{\circ}\right)$ was given 2; North-West $(292.5$ - 337.5 $)$ was associated with 3; Flat (-1) was given 4; East $(67.5$ $\left.112.5^{\circ}\right)$ was associated with 5; West $\left(247.5-292.5^{\circ}\right)$ was associated with 6; South (157.5 $202.5^{\circ}$ ) was given 7 , South-East $\left(112.5-157.5^{\circ}\right)$ was associated with 8 ; and the areas with slopes facing South-West $\left(202.5-247.5^{\circ}\right)$ was associated with 9 as the corresponding forest fire risk index value. Given the fact that wind speed and direction is a key factor which is highly influenced by altitude and aspect, and has a strong effect on fire spread, it would have been better to incorporate the factor. However, there was no nearby station which could avail such datasets, and hence, the research was carried out in a data-scarce environment and adapted to the situation to ensure the accuracy of the predictions.

\section{Final Topographic Risk Input Factor Map}

Ranks and weights for the topographic factors were generated using the Analytic Hierarchy Process (AHP), using the Based on the interview conducted with park staff and conservation experts in the region. The slope was highly weighted with 0.72 , whereas the elevation was the least weighted parameter with 0.08 . Table 4 presents the average factor's ranks as per the responses by the interviewed conservation experts in the region.

Table 4: Average Factor's Ranks Proposed by Conservation Experts in the Region 


\begin{tabular}{llll}
\hline Ranking & Slope & Aspect & Elevation \\
\hline Slope & 1 & 5 & 7 \\
Aspect & 0.2 & 1 & 3 \\
Elevation & 0.143 & 0.333 & 1 \\
Total & 1.343 & 6.333 & 11 \\
\hline
\end{tabular}

Furthermore, the specific weights were computed for each topographic factor (table 4), before proceeding with the production of the final topographic risk factor map. Remarkably, a significant consistency in the ranks proposed by different experts was obtained, with a Consistency Index (CI) of 0.03 as presented in table 5. As Saaty (1980) indicates that a CI with a ratio close to 0 indicates a perfect consistency in the judgments, the obtained ratio of 0.03 (close to 0 ) indicates a very high consistency, which can be judged as reliable.

Table 5: Obtained Weights using AHP Method

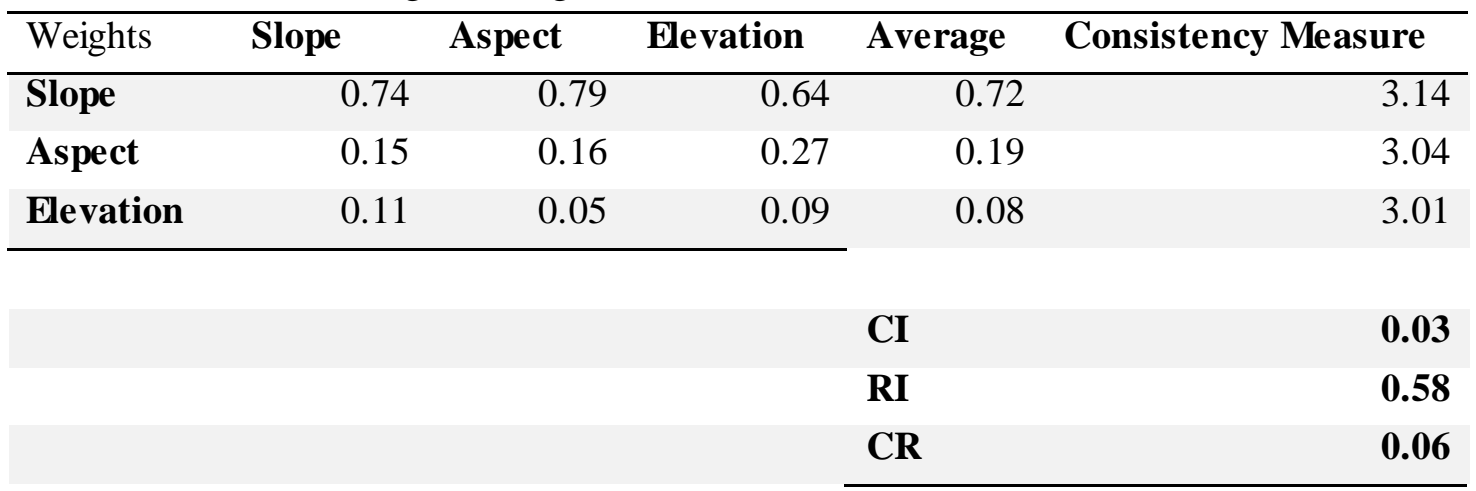

Using the obtained weights in table 5, the final topographic risk input factor map was constructed using the following empirical relationship:

Topographic Risk Factor Index $=(0.72 *$ Slope $)+(0.19 *$ Aspect $)+(0.08 *$ Elevation $)$

The produced final topographic risk input factor map (Figure 5. b.), indicates that areas of the Virunga massif with a high risk of wildfire based on the topographic factors are mainly located around the volcanoes, whereas the areas with low risk are observed in Mikeno sector's portion of Virunga National Park in DRC, in the North-East of Mikeno Volcano.

\section{c. Ignition Risk Factors}

\section{Illegal Activities}

Many cases of illegal activities related to forest fire are recorded and reported every year. For instance, from 2005 up to 2014, a total of 1,263 cases of illegal activities associated with forest fire have been reported in the Virunga massif. In this regard, the current study has analysed the concentration (density) of illegal activities in different locations of the ecosystem, with the assumption that areas with high density (high occurrence of illegal activities per location) are the one with the highest probability to catch forest fire (Figure 4. d.). The computed illegal activities density map was reclassified into 5 classes, and each class was assigned with a corresponding risk 
fire index, with areas presenting the highest density of illegal activities (class 5) located in South and Eastern part of the Virunga massif. Generally, areas with the highest fire risk based on observed illegal activities were found to cover an area of about $1.1 \%$ of the entire ecosystem (Figure 4. d.).

\section{Proximity to Beehives}

Since the beekeeping requires fire ignition especially during the honey harvesting process, this study has considered this as an important factor which poses a risk of forest fire occurrence. In this regard, a total of 38 beehive sites were found around the forest and their locations were mapped, and their proximity to different parts of the ecosystem was computed (Figure 4. e.). The obtained beehives proximity was reclassified into 6 classes for which a corresponding fire risk index was associated. The first class $(0-50 \mathrm{~m})$ was associated with 9 meaning that it has the highest potential to cause the forest fire, the second class $(51-100 \mathrm{~m})$ was given 6 , the third class $(101-200 \mathrm{~m})$ was assigned 4 , the fourth class $(201-1000 \mathrm{~m})$ was assigned 3 , the fifth class $(1001-2000 \mathrm{~m})$ was assigned 2, and the class with above $2000 \mathrm{~m}$ from the locations of the beehives was attributed with 1 indicating the lowest potential to cause the fire.

\section{Final Ignition Risk Input Factor Map}

The interviewed conservation experts indicated that the existing illegal activities associated with fire ignition such as poachers' camp beehive setting, honey gathering, and charcoal burning, are more important for the forest fire risk, than the proximity to beehives, with an overall weight of 0.66 for illegal activities against 0.34 for proximity to beehives (Figure 2).

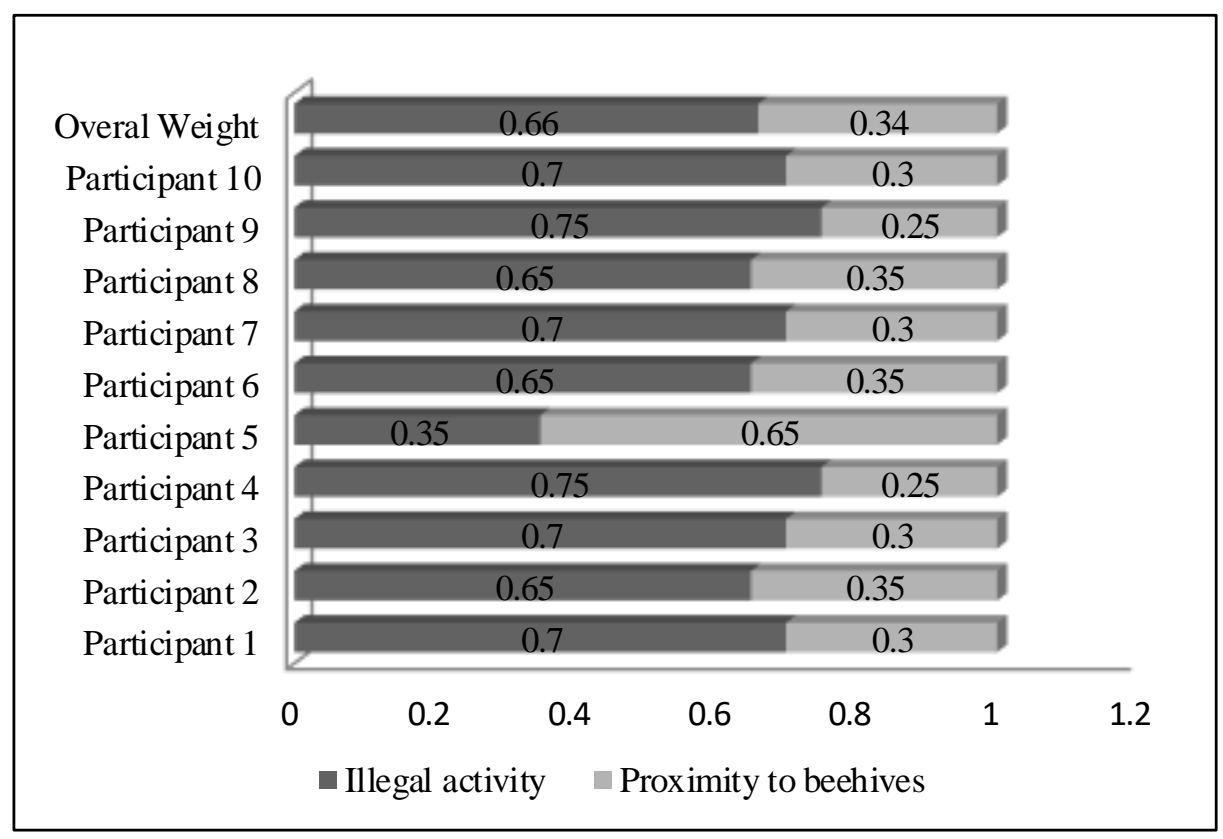

Figure 2: Weights Proposed by Conservation Experts in the Region for Ignition Risk Factors

Following the guide given by the interviewed conservation experts in the region (Figure 2), the final ignition risk input factor map (Figure 5. c.) was constructed using the following empirical relationship. 
Final Ignition Risk Factor Index $=(0.66 *$ Illegal activities $)+(0.34 *$ Proximity to beehives $) \quad$ Eq. 4

It has been observed that the Far Southern and Far Western parts of the Virunga massif which also presented the highest density of illegal activities are also exposed to the highest forest fir risk based on the ignition risk factors (Figure 5. c.)

\section{d. Detection Risk Factor}

\section{Visibility from Human Settlement}

The visibility of forest areas to the neighbouring human settlement has also been considered as a key aspect contributing to the wildfire risk since if there is a forest fire, people from the neighbouring settlement can contribute to the fire extinction, if visible to them. In this regard, a total of 671 points, corresponding to observer features in the neighbouring settlement, were randomly generated to produce forest visibility from human settlement. The obtained visibility map indicates that most of the Virunga massif forest (96.7\%) is not visible to human settlement (Figure 4. f.), and hence, classified in high risk of a devastating forest fire. The lower the visibility, the higher the index.

\section{Visibility from Roads}

Similarly to the visibility to the nearest human settlement, it is assumed that the parts of the forest not visible to the nearby roads are at high risk of the forest fire since it would be very late before the people in nearby roads can notice the fire and provide the support for the extinction. In this regard, 823 polylines corresponding to the existing nearby roads were produced and helped to compute the visibility of different parts of the Virunga massif from the roads (Figure 4. g.). It was found that about 95.7 if the Virunga massif is not visible to the nearby roads, putting the major part of the ecosystem into the high-risk class. The two types of visibility (to nearby settlements and roads) have helped to attribute the corresponding fire risk indicates to the 4 visibility classes, where class 1 was assisted with 1, class 2 was assigned 2, class 3 was assigned 3 and visibility class 4 was assigned 4 indicating the high risk of the forest fire.

\section{Final Detection Risk Factor Map}

The responses of the interviewed conservation experts indicated that proximity to roads is more important in detecting forest fire upon its occurrence (overall weight $=0.555$ ) compared to proximity to human settlements (overall weight $=0.445$ ) as presented in the following Figure 3. 


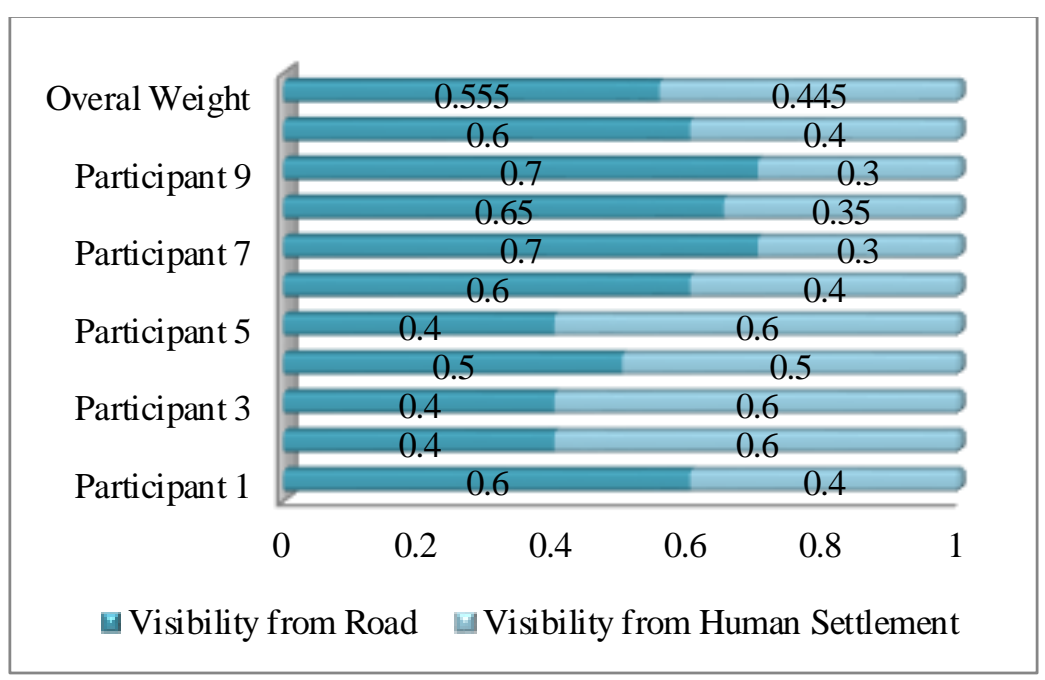

Figure 3: Weights Proposed by Conservation Experts in the Region for Fire Detection Risk Factors

Based on the obtained weights for the forest fire detection risk factors (Figure 3), the empirical relationship for the two visibility factors was constructed using the following equation:

Detection Risk Factor Index $=\left(0.555^{*}\right.$ Visibility from roads $)+\left(0.445^{*}\right.$ visibility from human settlements)

The relationship in Eq. 5 was executed using the raster calculator function of the ArcGIS software and resulted in the map in Figure 5.d, from which it could be observed that the far interior parts of the forest not visible from the observers on roads and human settlements are at high risk that once they catch fire, the fire detection will be delayed and hence, the fire would be devastating. The lowest risk was associated with areas around the volcanoes cones which are highly visible to both roads and settlements.

\section{e. Response Risk Factor}

The response is an important factor in forest fire risk modelling, as it indicates the amount of time and required effort to reach to areas affected by the fire. In this regard, the response risk has been analysed using key variables, given the fact that they contribute to the changes in the level of response risk. The considered variables include slope and elevation, and proximity to roads. In this regard, given the obtained information from the conservation experts, the slope was reclassified into 9 classes and assigned corresponding risk index factor, where areas with a slope between 0 and $10 \%$ have been assigned $1 ; 11-25 \%$ assigned $2 ; 26-40 \%$ assigned $3 ; 41-55 \%$ assigned 4; $56-70 \%$ attributed with 5; $71-85 \%$ attributed with 6; $86-100 \%$ attributed with 7; $101-120 \%$ assigned 8 and areas with a slope above $120 \%$ has been assigned 9 indicating the highest risk of these areas being not easily reached in due time for the forest fire extinction.

Furthermore, the elevation has been reclassified in 5 classes per the conservation experts feedbacks, and areas with elevation ranging between $1800 \mathrm{~m}$ and $2400 \mathrm{~m}$ were assigned with a risk index value of 1; 2401 - $2700 \mathrm{~m}$ was assigned 2; 2701 - $3100 \mathrm{~m}$ was assigned 3; 3101 $3500 \mathrm{~m}$ was assigned 4; and areas with elevation above $3500 \mathrm{~m}$ were assigned with risk value of 
5 indicating the highest level of difficulties to reach these areas for the forest extinction. From the 5 classes of road proximity (Figure 4 . h.), the risk index value was assigned to each class based on the answers of the consulted conservation experts in the region, where the first class $(0-100$ m) was assigned with 1 ; second class $(101-200 \mathrm{~m})$ assigned with 2 ; third class $(201-1000 \mathrm{~m})$ was assigned with 3; fourth class (1001 - $2000 \mathrm{~m})$ was assigned with 4, and the fifth class of areas located farther than $2000 \mathrm{~m}$ from the nearest roads have been assigned with 5 indicating the highest response risk.

\section{Final Responses Risk Factor Map}

After the obtained values from the answers by the conservation experts, the ranking has been produced using the AHP method (Table 6).

Table 6: Ranks Attributed to Response Factors from the Conservation Experts Answers

\begin{tabular}{llll}
\hline Ranking & Proximity to roads & Slope & Elevation \\
\hline Proximity to roads & 1 & 3 & 5 \\
Slope & 0.333 & 1 & 3 \\
Elevation & 0.2 & 0.333 & 1 \\
Total & 1.533 & 4.333 & 9 \\
\hline
\end{tabular}

Before proceeding to the final equation to compute the response risk factor, it was important to generate the weights for each of the response risk factors, and check the consistency values as presented by the following table 7 .

Table 7: Weights Produced for Response Risk Factors and Corresponding Consistency Values

\begin{tabular}{|c|c|c|c|c|c|}
\hline Weights & $\begin{array}{l}\text { Proximity to } \\
\text { roads }\end{array}$ & Slope & Elevation & Average & Consistency Measure \\
\hline Slope & 0.652 & 0.692 & 0.556 & 0.633 & 3.072 \\
\hline Proximity to roads & 0.217 & 0.231 & 0.333 & 0.26 & 3.033 \\
\hline \multirow[t]{4}{*}{ Elevation } & 0.13 & 0.077 & 0.111 & 0.107 & 3.011 \\
\hline & & & & CI & 0.01935734 \\
\hline & & & & $\mathbf{R I}$ & 0.58 \\
\hline & & & & CR & 0.033374725 \\
\hline
\end{tabular}

From the weights in Table 7, the response risk factor index has been computed using the empirical relationship constructed using the following equation

Response Risk Factor Index $=(0.633 *$ Slope $)+(0.26 *$ Proximity to roads $)+(0.107 *$ Elevation $) \quad$ Eq. 6

The obtained final response risk factor index map (Figure 5. e.) indicated that locations of the Virunga Massif inside the ecosystem are associated with the highest response risk compared to those close to the forest edge, closer to roads. Moreover, areas with steeper slopes such as around the volcanoes cones, are also exposed to the highest risk. 

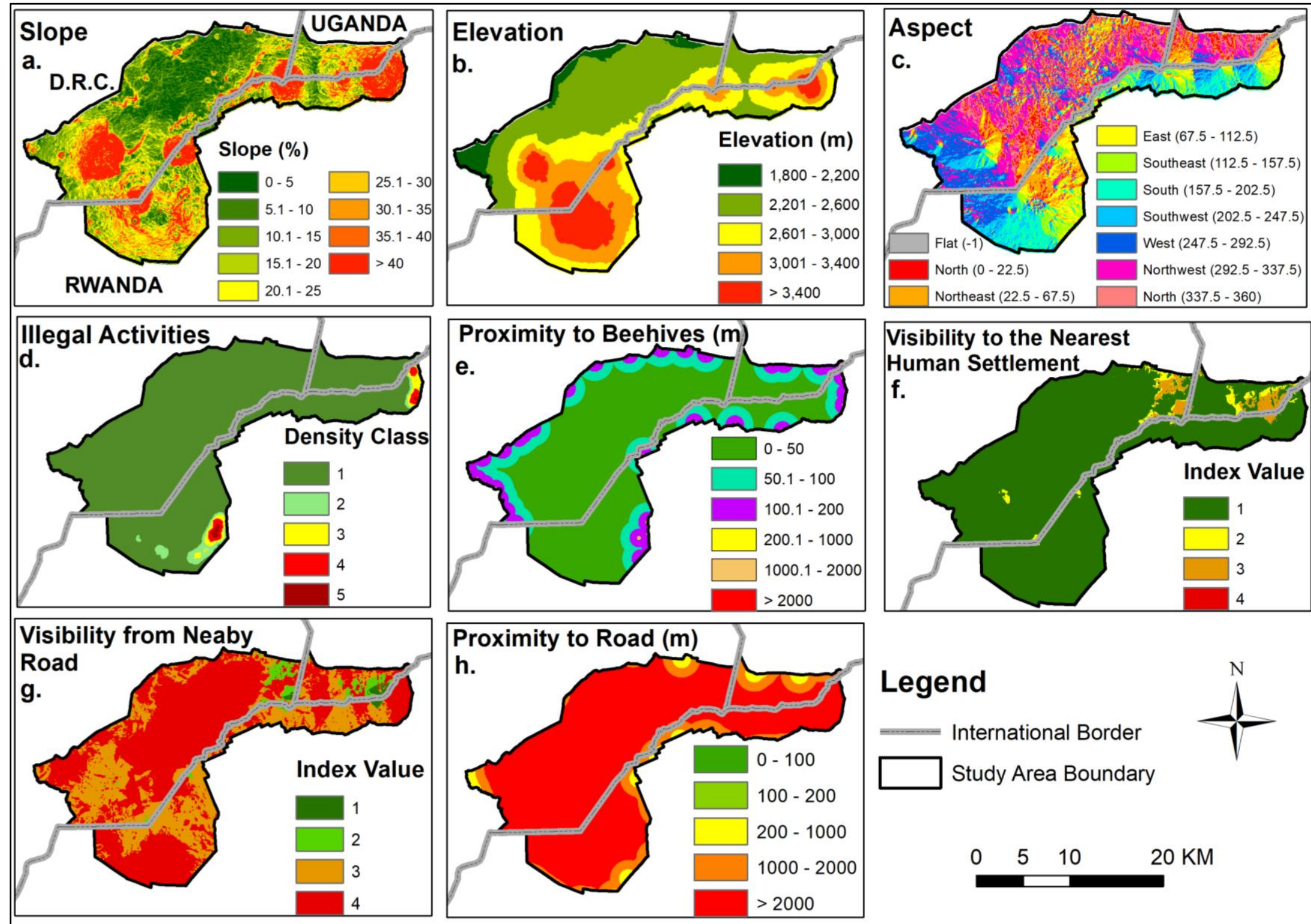

\section{Legend}

= International Border

$\square$ Study Area Boundary
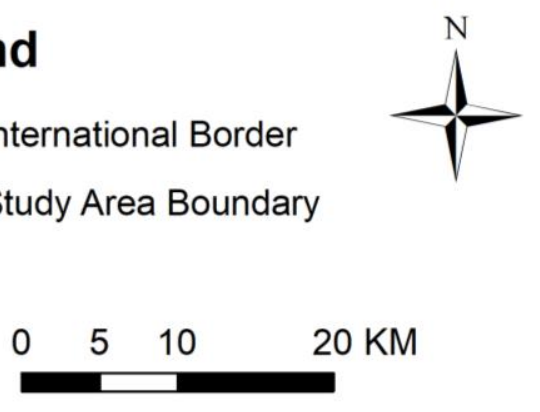

Figure 4: Input Factor and Correspondice Index Values for the Final Model Computation 


\subsection{Final Spatial Model of the Virunga Massif Forest Fire Risk}

The final ranks and weights obtained using the AHP pairwise comparison, have been used to integrate all the forest fire risk input factors into the final spatial forest fire risk model of the Virunga massif. The obtained final weights started with ignition risk factors which scored the highest (0.496), followed by topographic factors which scored 0.243 , then fuel risk factors which scored 0.144 , then response risk factors which scored 0.077 , and lastly detection risk factors which scored 0.040 indicating the least contribution to the final spatial forest fire risk model for the ecosystem. These weights were used and the final Virunga massif spatial forest fire risk model was constructed using the following empirical relationship:

Final Forest Fire Risk Model $=(0.496 *$ Ignition Risk $)+(0.243 *$ Topographic Risk $)+$ $(0.144 *$ Fuel Risk $)+(0.077 *$ Response Risk $)+(0.040 *$ Detection Risk) Eq. 7

The final spatial model of the Virunga massif forest fire risk (Figure 5. f.) indicates that areas at the highest risk of forest fire area located in steep slopes around volcanoes cones, whereas the majority of areas inside the ecosystem were found to be at the lowest risk of the wildfire. 


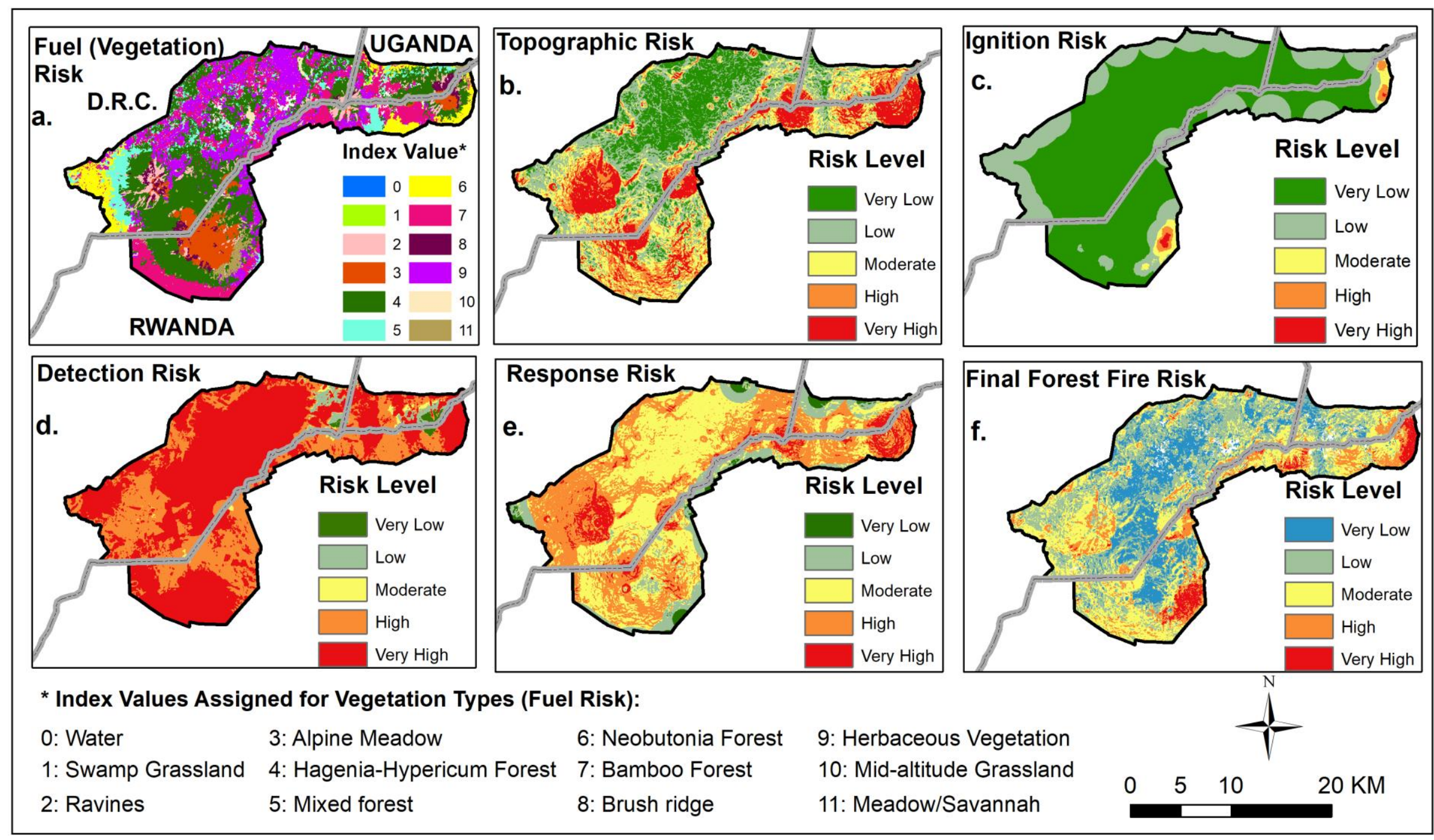

Figure 5: Final Factor Input Maps (a, b, c, d and e) and the Final Spatial Model for the Forest Fire Risk in Virunga Massif (f) 


\section{Discussion}

The final spatial model of the Virunga massif forest fire risk has been achieved through the combination of key contributing factors which integrated the, 1) vegetation cover (fuel) effect on forest fire risk; 2) topography effect on the fire risk model; 3) ignition risk; 4) fire detection risk; and 5) response risk. First, vegetation types or referred to as fuel is an important component of forest fire since it provides burnable materials necessary to have the fire (Chiuveco and Salas, 1996). The forest in Virunga massif is the humid tropical forest, receiving abundant rain throughout the year, and hence, this can contribute to the reduction of the wildfire risk. This has been confirmed by the feedback from the consulted conservation experts in the region who indicated that the vegetation type can occupy the third place among the key factors influencing the forest fire in the area. Nevertheless, in case of a prolonged dry season, vegetation types such as meadow savannah, mid-altitude grassland and bamboo forest dry out and hence increased the wildfire risk to fire. Changes in the climate which are predicted will also contribute to increased fire risk in these tropical ecosystems (Basabose K. and Gray, 2010).

Second, topography constitutes the most constant factor in the wildfire, and contribute much to its spread, with a strong influence on fuels, weather, surface energy, and water budgets based physical laws (Schroeder and Buck, 1970). Additionally, landforms affect the amount of solar radiation incident on a site, wind flow patterns, precipitation patterns, and evaporation, which in turn, affect the frequency duration of flammable periods and a site's ability to grow biomass (Goldammer and Ronde, 2004). In this study, topography was attributed second importance in influencing the forest fire in Virunga massif. Moreover, the mountainous nature of the study area increases the risk of fire damage when there is a fire outbreak. The results showed that areas around volcanoes cones were the most vulnerable to fire. This is consistent with similar studies undertaken in high altitude and steep areas (Santiago and Kheladze, 2011; Heikkilä, et al., 2010; Rathaur, 2005) and contrast with other studies which were undertaken in low altitude areas (Mohammed et al., 2009; Jaiswal et al., 2002), where the topography was given low importance in forest fire modelling process. These findings were supported by information received from interviews with different conservation partners who participated in the extinguishing fire in 2009 who mentioned that topography played a big role in the spread of fire and increased the speed by which fire was spreading to other areas. Muhabura area which affected is among the steepest areas in the whole Virunga Massif.

Third, ignition as a process by which fire is initiated and is directly linked with the source of heat; has been associated with great importance in the fire triangle (Heikkilä et al., 2010). In this study, ignition risk has been identified as the foremost factor in forest fire risk and has been linked to illegal anthropogenic activities in the ecosystem such as beehives setting, honey gathering, poaching, and charcoal burning inside the forest. From the responses by the consulted conservation experts, ignition risk was ranked the highest in the final forest fire model. Illegal activities considered were not evenly distributed across the forest and were limited to certain areas. However, the beehives sites were distributed all along the park boundaries, making these 
areas highly vulnerable. These findings are different from few other forest fire modelling studies which have been taking into account the distance to human settlement and roads as the main factors contributing to fire ignition (Deeming et al., 1978; Artsybashev, 1983; Calabri, 1984; Chuveco and Congalton, 1989; Chiuveco and Salas, 1996; Bovio and Camia, 1997; Gouma and Sereli, 1998; Jaiswal et al., 2002; Erten et al, 2002; Rawat, 2003; Rathaur, 2006). In the study area, the forest is surrounded by a high-density population and in many cases, human settlements are close to the forest boundaries and no road passes through the forest. Consequently, this pattern cannot make the parameters above relevant to the model.

Fourth, fire detection risk has been considered an important and integral part of fire management and fire suppression since fire control and extinction cannot happen without detecting and locating fire (Santiago and Kheladze, 2011). This study's results showed that fire is most likely to be detected from the road than from settlement. This due to the topography of the area, since in the hilly area, people living close to the forest are likely to see a small part of the forest than people away from the forest. From the detection risk model, areas located in the interior of the forest, mainly in PNVi Mikeno sector were identified to be most vulnerable to fire due to their limited visibility from both human settlement and roads.

Finally, the response risk factor has also been taken into account, indicating the amount of time and effort required to reach areas of the forest in case of fire. In the study area, the topography of the area and road and trail network are the main constraints in case people are mobilized and transported from far locations to the forest for controlling and extinguish the fire. The areas far from roads and the forest edge with a steep slope and higher elevation were identified to be at high risk. Based on expert knowledge and interviews with people involved in 2009 fire extinction, the slope was ranked as the most important constraint factor in forest fire control as it makes fire extinction teams tired and affects their performance.

The spatial fire risk model in the Virunga massif that was produced through the integration of all the five above-mentioned contributing factors has shown that areas with steep slopes and high concentration of illegal activities which require ignition are the ones posing a serious threat related to the wildfire risk in the area. This situation is exacerbated by the continued increase of the human population in the region with limited alternative livelihood means apart from agriculture. In the ignition risk factors, proximity to beehives did not play a significant role because the beehives sites are evenly distributed along the forest edge. This aspect was implemented after the 2009 fire event which was started by a beekeeper who was collecting honey from beehives in the park. However, beehives sites are still a risk-contributing factor given the fact that they are set at the forest edge, with many of them set along the buffalo wall (a stone wall constructed all along the forest edge to prevent buffaloes coming out to raid on crops in forest-surrounding gardens), and few of the community members try, still, to set the beehives inside the forest. Areas located in the inner part of the Virunga massif forest were attributed with a lower risk of fire. These are areas with gentle slopes in the Mikeno sector of Virunga National Park (DRC). 


\section{Conclusion}

It is widely known that forest fire depends on three main factors: fuel, heat and oxygen. However, the physical and social setting of the environment plays a significant role in fire occurrence, spread, and control. The obtained final spatial model of the forest fire risk in Virunga massif has indicated that the most contributing factors to the fire risk (occurrence and spread) in the ecosystem are ignition factors and topographic factors. Hence, the forest management is strongly advised to put serious restrictions, monitoring and control mechanisms on the ignition factors. Fuel factors did not contribute significantly to the forest fire model due to the physical characteristics of the study area. However, the prolonged dry seasons with a decrease in rainfall which is predicted because of the climate change, and hence, thus could become crucial in the future. Other important factors considered include detection and response factors, which eventually did not contribute significantly to the final spatial forest fire risk model. However, they could not be ignored since their contribution is regularly taken into consideration for forest fire management, especially during the occurrence of the fire event. The proposed fire risk model did not include some factors such as weather variables, i.e. temperature, rainfall, wind, etc. because it was difficult to get spatially accurate weather data since there were no meteorological stations in the proximity of the study area and the existing global data were coarse. The study indicates that there is a crucial need for the design of a fire management plan considering the risk severity of different risk areas of the final spatial forest fire risk model.

\section{Acknowledgements}

Authors would like to convey special gratitude to the Protected Areas Authorities in Virunga Massif, namely Rwanda Development Board (RDB), Uganda Wildlife Authority (UWA), and Institut Congolais pour la Conservation de la Nature (ICCN), for their assistance for both data provision and permission to work in the parks under their management. Special thanks are also given to the International Gorilla Conservation Programme (IGCP) authorities, and the University of Rwanda for the professional support provided for the achievement of this study.

\section{References}

Basabose, K. A. and Gray, M. (2010). Mountain Gorilla Conservation and Climate Change. In AWF, IGCP, and EcoAdapt. The Implications of Global Climate Change for Mountain Gorilla Conservation in the Albertine Rift. African Wildlife Foundation, International Gorilla Conservation Programme, EcoAdapt, John D. and Catherine T. MacArthur Foundation.

Chuvieco, E., Congalton R.G. (1989). Application of remote sensing and geographic information systems to forest fire hazard mapping. Remote Sensing of the Environment, 29, 147-159.

Chuvieco, E., Salas J. (1996). Mapping the spatial distribution of forest fire danger using GIS. International Journal of Geographical Information Systems, 10(3), pp. 333-345. 
Dong, X., Guofan, S., Limin, D., Zhanqing, H., Lei, T. \& Hu, W. (2006). Mapping forest fire risk zones with spatial data and principal component analysis, Science in China: Series E Technological Sciences 2006 Vol.49 Supp. I 140-149.

FAO. (2001). Global forest fire assessment 1990-2000. FRA Working Paper No. 55. Available online: www.fao.org/forestry/fo/fra/index.jsp

Goldammer, J.G. \& Jenkins, M.J. (eds.). (1990). Fire and ecosystem dynamics. Mediterranean and northern perspectives. The Hague, The Netherlands, SPB Academic Publishers.

Goldammer, J.G. \& Price C. (1998). Potential impacts of climate change on fire regimes in the tropics based on MAG-ICC and GISS GCM-derived lighting model. Climate Change, 39: 273-296.

Goldammer, J.G. \& C.de Ronde (eds.). (2004). Wildland Fire Management Handbook for SubSahara Africa. Global Fire Monitoring Center and Oneworldbooks, Freiburg - Cape Town, 432 p. (ISBN 1- 919833-65-X).

Heikkilä, T.V., Grönqvist, R., Jurvélius, M. (2010). Wildland fire management: a handbook for trainers: FAO.

IUCN/WWF (2000). Global review of forest fires. International Union for the Conservation of Nature and World Wide Fund for Nature (WWF). (2000). Gland: Switzerland.

IPCC (2015). Climate Change 2014: Impacts, Adaptation, and Vulnerability. Part A: Global and Sectoral Aspects. Contribution of Working Group II to the Fifth Assessment Report of the Intergovernmental Panel on Climate Change in Field, C.B., V.R. Barros, D.J. Dokken, K.J. Mach, M.D. Mastrandrea, T.E. Bilir, M. Chatterjee, K.L. Ebi, Y.O. Estrada, R.C. Genova, B. Girma, E.S. Kissel, A.N. Levy, S. MacCracken, P.R. Mastrandrea, and L.L. White (eds.). Cambridge University Press, Cambridge, United Kingdom and New York, NY, USA, $1132 \mathrm{pp}$

Jaiswal, R.K., Mukherjee, S., Raju, D.K., Saxena, R. (2002). Forest fire risk zone mapping from satellite imagery and GIS. International Journal of Applied Earth Observation and Geoinformation, 4 (pp.1-10).

Larsen, J. (2009). Wildfires by Region: Observations and Future Prospects. Earth Policy Institute, www.earthpolicy.org, November 2009.

Johnson, E. A, Gutsell S L. (1994). Fire frequency models, methods and interpretations. AdvEcol Res, 25: 239-287

Grégoire, J-M., Glénat, B., Janvier, P., Janodet, E., Tournier. A. (1998). Fire Activity in the Guyana Shield, the Orinoco, and Amazon Basins during March 1998. International Forest Fire News, September, pp. 39-41 
Kayijamahe, E. (2009). Spatial modelling of mountain gorilla (Gorilla beringeiberingei) habitat suitability and human impact. Master's Thesis, University of Twente, Faculty of GeoInformation and Earth Observation, ITC, Enschede, Netherlands.

Leblon, B., Bourgeau-Chavez, L., San-Miguel-Ayanz, J. (2012). Use of remote sensing in wildlife management. In Curkovic, S. (Ed), Sustainable development - authoritative and leading-edge content for environmental management (pp.55-82). Rijeka, Croatia: InTech

Mohammed, Y., Hussin, Y.A. and Quashie-Sam, S.J. (2009). Modelling forest fire risk using remote sensing and GIS: a case study of the transitional forest zone of Ghana. In: EOGC 2009: Proceedings of the 2nd international conference on earth observation for global changes, May 25-29, 2009, Chengdu, Sichuan, China, ed. by. Qingxi Tong and Deren Li. Beijing; Peking University, 2009. pp. 2138-2147.

Nepstad, D.C., Moreira, A.G. \& Alencar, A.A. (1999). Flames in the rain forest: origins, impacts and alternatives to Amazonian fires. Brasilia, Brazil, Pilot Program to Conserve the Brazilian Rain Forest.

Orozco, S. J., Hussin, Y.A., Weir, M. J. C., Mas, J. F. (2009). Fire hazard and control for Michoacan state, Mexico, in: EOGC 2009: Proceedings of the 2nd international conference on earth observation for global changes, May 25-29, 2009, Chengdu, Sichuan, China/ed by, Qingxi Tong and Deren Li, Beijing; Peking University, 2009. pp. 2148-2158

Rathaur, S. (2006). Fire risk assessment for tiger prey - base is Chilla range and vicinity: Rajaji National Park using remote sensing and GIS. University of Twente, Faculty of GeoInformation and Earth Observation, ITC, Enschede, Netherlands.

Sabuhoro, E., Wright, E. B., Powell B. R., Hallo C. J., Layton A. P. and Munanura, E. I. (2020). Perceptions and Behaviors of Indigenous Populations Regarding Illegal Use of Protected Area Resources in East Africa's Mountain Gorilla Landscape. Environmental Management 65, (2020): 410-419. DOI: https://doi. org/10.1007/s00267-020-01254-z

Santiago, S. \&Kheladze, N. (2011). GIS Wildland fire hazard modelling in Georgia. Matra Project Report, Caucasus Environmental NGO Network.

Schroeder, M.J.; Buck, C.C. 1970. Fire weather. a guide for application of meteorological information to forest fire control operations. U.S. Department of Agriculture, Washington, D.C. Agriculture Handbook 360. 229 p.

Uhl, C. \& Kauffman, J. B. (1990). Deforestation, fire susceptibility and potential tree responses to fire in the eastern Amazon. Ecology, 71, 437-449. (doi:10.2307/1940299). 